\title{
Resident Outcomes and Perspectives Over 2 Years of a New Scholarship Curriculum
}

Katherine R. Standish, MD; Sam C. Gonzalez, MD; Victor Roy, MD, PhD;

Chelsea M. McGuire, MD, MS; Katherine A. Gergen Barnett, MD; Robert B. Saper, MD, MPH

\begin{abstract}
BACKGROUND AND OBJECTIVES: Scholarship is recognized as a challenge in many family medicine residency programs. Among evaluations of scholarship curricula, few describe resident experiences of such interventions. To bridge this gap in knowledge, we measured resident confidence, satisfaction, and participation before and after implementing a new scholarship curriculum.
\end{abstract}

\begin{abstract}
METHODS: The redesigned curriculum included a structured project timeline, resident research in progress meetings, faculty mentorship, scholarly skills workshops, and mentored journal clubs. We conducted a curriculum evaluation via surveys of residents prior to implementation and after years 1 and 2, measuring satisfaction with the scholarly environment and opportunities, and confidence and participation in specific scholarly activities using Likert scales from 1 (least confidence) to 5 .
\end{abstract}

RESULTS: Compared to baseline $(n=28)$, after 2 years $(n=27)$ of the curriculum, residents reported increased mean confidence in critical appraisal of scientific articles $(2.6 \pm 1.1$ to $3.3 \pm 0.7, P=.007)$, carrying out a scholarly project (2.5 \pm 0.8 to $3.4 \pm 1.0, P=.005)$, and writing an abstract (3.0 \pm 0.8 to $3.8 \pm 0.7$, $P=.002)$. As compared to the first year, more residents in the second year participated in quality improvement projects $(7.1 \%$ vs $29.6 \%, P=.031)$ and wrote conference abstracts $(10.7 \%$ vs $37.0 \%, P=.022)$. Over the same period, those very satisfied with the scholarly environment increased from $0(0 \%)$ to $8(29.6 \%, P=.017)$. The June 2020 survey identified increased interest in scholarship because of the antiracism movement (51.9\%) and COVID-19 pandemic $(40.7 \%)$.

CONCLUSIONS: Implementation of a redesigned scholarship curriculum was associated with increases in family medicine resident scholarship confidence and satisfaction.

(Fam Med. 2021;53(6):461-6.)

doi: 10.22454/FamMed.2021.267781

D espite the pressing need for primary care physicians to investigate and address the many challenges in our health care environment, scholarship in family medicine continues to lag behind other specialties. ${ }^{1-3}$ Great variation exists in how residency programs Medical Education (ACGME). ${ }^{7}$
Across disciplines, residency programs have implemented a variety of interventions to support resident scholarship and research training, many with documented success increasing scholarly output. ${ }^{8}$ However, few of these studies report on resident experiences and satisfaction with scholarship curricula or confidence in scholarly activities. ${ }^{9}$ This article addresses these gaps by sharing resident outcomes and perspectives over 2 years of a redesigned scholarship curriculum.

\section{Methods}

At Boston University, family medicine residents' satisfaction with the scholarly environment and opportunities were the lowest measures on the 2017 ACGME annual resident survey. In response, residents expressed a desire for stronger scholarship training. In 2018-2019, a faculty member (R.S.) and postgraduate year-3 (PGY-3) resident (K.S.) led the design and implementation of a longitudinal curriculum based on resident feedback, discussions with departmental leadership, and review of published curricula and national guidelines. ${ }^{5,10-15}$

meet scholarly activity training requirements. ${ }^{4,5}$ In family medicine residencies, scholarly activity was slow to be incorporated, ${ }^{6}$ and is a common deficiency cited by the Accreditation Council of Graduate
From Boston Medical Center, Boston, MA (Drs Standish, Gonzalez, Roy, Gergen Barnett, and Saper); Boston University School of Medicine, Boston, MA (Drs Standish, Gergen Barnett, McGuire and Saper); Boston University Institute for Health System Innovation and Policy, Boston, MA (Drs McGuire and Gergen Barnett); and Cleveland Clinic, Cleveland, $\mathrm{OH}$ (Dr Saper). 
The curriculum included a 2-year project timeline, monthly researchin-progress meetings, monthly journal clubs, and periodic scholarly skills workshops (Table 1). The curriculum coordinators provided regular feedback to residents and facilitated connection to faculty mentors.

We administered anonymous resident surveys via email prior to curriculum implementation (baseline, July 2018) and after the first (May 2019) and second (June 2020) years of implementation. The survey assessed attitudes, confidence, and participation in scholarly activities and processes (eg, abstract writing regardless of conference acceptance). We included three questions from the ACGME annual resident survey regarding satisfaction with scholarship. In June 2020 (year 2), we added questions regarding the effects on resident scholarship of the COVID-19 pandemic and antiracism movement, as these events were broadly affecting many domains of the residency program.

We treated each year as an independent sample, as residents entered and left the residency. We performed analyses of variance with a multiple comparisons procedure using Tukey's test to assess differences in means across three survey time points, $t$ tests of independent samples across two time points, and $\chi^{2}$ tests of independence for categorical variables. Significance was defined as $P \leq .05$ for all tests. We conducted analyses using SAS software (version 9.4, SAS Institute, Cary, NC). Though not designed as a mixed-methods study, we reviewed responses to open-ended questions to contextualize quantitative findings. The Boston University Institutional Review Board deemed the study exempt.

\section{Results}

Overall, 48 residents participated in the curriculum over 2 years. Compared to year 1 , at year 2 more residents conducted a quality improvement project $(29.6 \%$ vs $7.1 \%$ $P=.031)$ and wrote an abstract for conference submission (37.0\% vs $14.8 \%$ vs $P=.022$, Table 2 ). Compared to baseline, residents at the end of

Table 1: Components and Timeline of Scholarship Curriculum and Scholarly Project, Boston Medical Center Family Medicine Residency Program

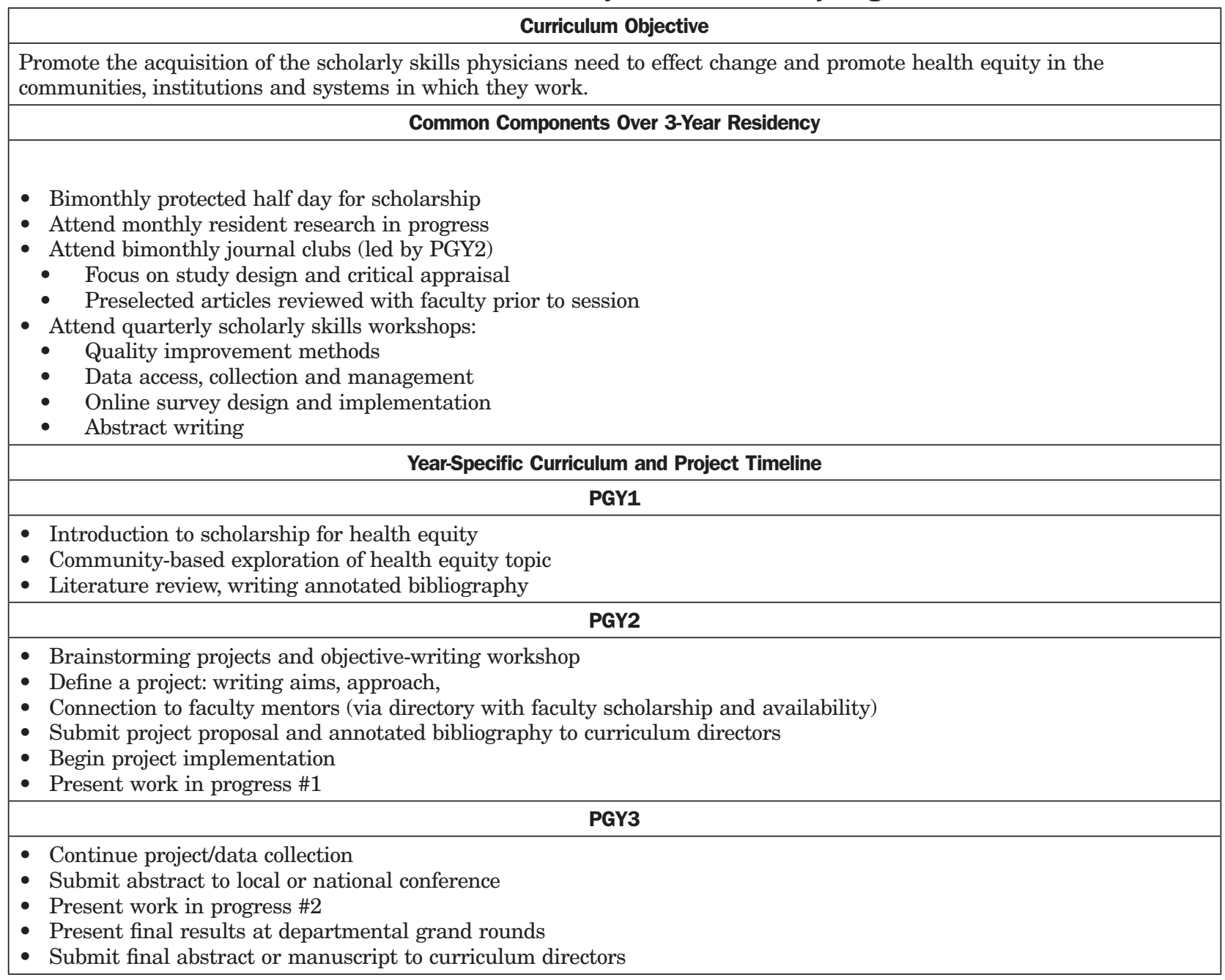


Table 2: Participation and Confidence in Scholarly Activities, BU FM Residents, 2018-2020

\begin{tabular}{|c|c|c|c|c|}
\hline & $\begin{array}{c}\text { Baseline } \\
\mathrm{n}=28(\%)\end{array}$ & $\begin{array}{c}\text { Year } 1 \\
n=28(\%)\end{array}$ & $\begin{array}{c}\text { Year } 2 \\
\mathrm{n}=27(\%)\end{array}$ & P Value ${ }^{a}$ \\
\hline \multicolumn{5}{|l|}{ Residency Year Among Survey Respondents ${ }^{b}$} \\
\hline PGY1 & $9(32.1)$ & $11(39.3)$ & $10(37.0)$ & \\
\hline PGY2 & $12(42.9)$ & $9(32.1)$ & $8(29.6)$ & \\
\hline PGY3 & $7(25.0)$ & $8(28.6)$ & $9(33.3)$ & \\
\hline \multicolumn{5}{|l|}{ Confidence in Scholarly Activities (Mean \pm SD) } \\
\hline Critically assess peer reviewed article & $2.6 \pm 1.1$ & $3.2 \pm 0.9 \mathrm{c}$ & $3.3 \pm 0.7^{\mathrm{c}}$ & .007 \\
\hline Carry out literature review & $2.7 \pm 1.1$ & $3.1 \pm 1.2$ & $3.7 \pm 0.7^{\mathrm{c}}$ & .002 \\
\hline Conduct quality improvement project & $2.2 \pm 0.9$ & $2.5 \pm 1.0$ & $3.0 \pm 0.7^{\mathrm{c}}$ & .008 \\
\hline Conduct scholarly project & $2.5 \pm 0.8$ & $3.0 \pm 1.1$ & $3.4 \pm 1.0^{\mathrm{c}}$ & .005 \\
\hline Develop research question and protocol & $2.4 \pm 1.0$ & $3.0 \pm 0.9$ & $3.2 \pm 0.9^{c}$ & .004 \\
\hline Write conference abstract & $3.0 \pm 0.8$ & $3.5 \pm 1.0$ & $3.8 \pm 0.7^{\mathrm{c}}$ & .002 \\
\hline Write manuscript for peer review & $2.3 \pm 1.1$ & $2.6 \pm 1.0$ & $2.9 \pm 1.0$ & .15 \\
\hline \multicolumn{5}{|c|}{ Scholarly Activity Participation Reported by Residents ${ }^{d}$} \\
\hline Lead a journal club & & $15(53.6)$ & $16(59.3)$ & .67 \\
\hline Participated in research & & $11(39.3)$ & $9(33.3)$ & .65 \\
\hline Participated in quality improvement & & $2(7.1)$ & $8(29.6)$ & .03 \\
\hline Submitted a conference abstract (whether or not accepted) & & $3(10.7)$ & $10(37.0)$ & .022 \\
\hline Drafted a paper for peer review (whether or not accepted) & & $4(14.3)$ & $2(7.4)$ & .41 \\
\hline
\end{tabular}

Abbreviations: BU FM, Boston University Family Medicine; SD=standard deviation.

${ }^{a} \chi^{2} P$ values are provided for categorical data (participation in scholarly activities) and analysis of variance (ANOVA) was performed for continuous data. For ANOVA, the asterisk indicates significant difference between baseline and the starred year.

${ }^{\mathrm{b}}$ Baseline and end of year 1 survey response rates were both 77.8\%, among 36 residents in the program AY 2018-2019. The end of year 2 survey response rate was $67.5 \%$, among 40 residents in AY 2019-200.

'Significantly different from baseline in multiple comparisons analysis using Tukey's test

${ }^{\mathrm{d}}$ Data on scholarly activity participation reported by residents was not available at baseline. Most projects were conducted individually; in year 2 one resident pair did a quality improvement project together.

year 2 reported greater confidence in critical appraisal of scientific articles (3.3 \pm 0.7 vs. $2.6 \pm 1.1, P=.007)$, carrying out a scholarly project in residency ( $3.4 \pm 1.0$ vs $2.5 \pm 0.8, P=.005)$, and writing an abstract $(3.8 \pm 0.7 \mathrm{vs}$ $3.0 \pm 0.8, P=.002$ ).

More residents reported that faculty were very/extremely effective at creating an environment of scholarship in years 1 (17.9\%) and $2(29.6 \%)$ than at baseline $(0 \%, P=.017$, Table 3). Most PGY-2 and PGY-3 residents reported satisfaction with mentorship, however approximately onequarter did not feel their mentor had relevant scholarly expertise. In year $2,62.9 \%$ stated they would like more interaction with research faculty, a sentiment echoed in narrative survey responses (Table 4). Residents reported increased interest in scholarship because of the antiracism movement (51.9\%) and COVID-19 pandemic (40.7\%), and these events caused over one-third of residents to change projects or protocols.

\section{Discussion}

This is one of only a few studies that report a positive association between a new scholarship curriculum and confidence in scholarly skills, ${ }^{16,17}$ particularly those skills emphasized by the curriculum..$^{18,19}$ Unlike other programs, ${ }^{4,8}$ we identified no increase in writing manuscripts, but did observe increases in abstract submissions, possibly paving the way for later publication. Strong research mentorship may be the missing ingredient for increasing manuscript output, ${ }^{4,9}$ however, increased participation and interest are also important intrinsic motivations for scholarship. ${ }^{20}$ Reflecting the wider impact on research in 2020, the COVID-19 pandemic and renewed focus on race impacted residents as their interest in scholarship increased and many shifted to studying pandemic-related disparities. Residents reported mixed satisfaction with faculty mentorship, citing in narrative responses a desire for more faculty availability, expertise, and a departmental culture of scholarship. Despite these reported shortcomings, resident satisfaction with the scholarly environment increased, which may reflect satisfaction with the curriculum, although opportunities for faculty-sponsored scholarship remained low. ${ }^{21}$ 
Table 3: Attitudes and Satisfaction With Scholarship and Mentorship, BU FM Residents, 2018-2020

\begin{tabular}{|c|c|c|c|c|}
\hline & $\begin{array}{l}\text { Baseline } \\
\mathrm{n}=28(\%)\end{array}$ & $\begin{array}{c}\text { Year } 1 \\
n=28(\%)\end{array}$ & $\begin{array}{c}\text { Year } 2 \\
n=27(\%)\end{array}$ & $P$ Value \\
\hline \multicolumn{5}{|c|}{ Scholarship and Curriculum } \\
\hline $\begin{array}{l}\text { Faculty effectiveness in creating an environment of } \\
\text { scholarship and inquiry }\end{array}$ & & & & .017 \\
\hline Not or slightly effective & $14(50.0)$ & $9(32.1)$ & $5(18.5)$ & \\
\hline Somewhat effective & $14(50.0)$ & $14(50.0)$ & $14(51.9)$ & \\
\hline Very/extremely effective & $0(0.0)$ & $5(17.9)$ & $8(29.6)$ & \\
\hline $\begin{array}{l}\text { Satisfaction with opportunities program provides to } \\
\text { participate in scholarship }^{\mathrm{a}}\end{array}$ & & & & .30 \\
\hline Not or slightly satisfied & $12(42.9)$ & $10(35.7)$ & $9(33.3)$ & \\
\hline Somewhat satisfied & $13(46.4)$ & $13(46.4)$ & $7(25.9)$ & \\
\hline Very/extremely satisfied & $3(10.7)$ & $5(17.9)$ & $9(40.7)$ & \\
\hline $\begin{array}{l}\text { Importance of scholarship and research in residency } \\
\text { curriculum }^{\mathrm{a}}\end{array}$ & & & & .60 \\
\hline Not at all/slightly important & $9(32.1)$ & $4(14.3)$ & $6(22.2)$ & \\
\hline Somewhat important & $11(39.3)$ & $8(28.6)$ & $8(29.6)$ & \\
\hline Very/extremely important & $8(28.6)$ & $16(57.1)$ & $13(48.1)$ & \\
\hline $\begin{array}{l}\text { Likelihood scholarship/research will be part of career after } \\
\text { residency }\end{array}$ & & & & .31 \\
\hline Very unlikely/unlikely & $9(32.1)$ & $6(21.4)$ & $7(25.9)$ & \\
\hline Neither unlikely nor likely & $10(35.7)$ & $13(46.4)$ & $6(22.2)$ & \\
\hline Likely/very likely & $9(32.1)$ & $9(32.1)$ & $14(51.9)$ & \\
\hline Satisfaction with new scholarship curriculum & & & & .23 \\
\hline Not or slightly satisfied & & $5(17.9)$ & $4(14.8)$ & \\
\hline Somewhat satisfied & & $11(39.3)$ & $6(22.2)$ & \\
\hline Very/extremely satisfied & & $12(42.9)$ & $17(63.0)$ & \\
\hline \multicolumn{5}{|l|}{$\begin{array}{ll} & \text { Mentorship } \\
\end{array}$} \\
\hline Mentor is family medicine faculty (vs other department) & & $12(70.6)$ & $11(64.7)$ & .25 \\
\hline Mentor has relevant scholarly expertise & & $13(76.5)$ & $10(71.4)$ & 1.00 \\
\hline Desires more interaction with research faculty & & & $17(62.9)$ & .43 \\
\hline \multicolumn{5}{|l|}{ Satisfaction with mentorship } \\
\hline Not at all satisfied & & $3(17.7)$ & $1(7.1)$ & \\
\hline Somewhat satisfied & & $6(35.3)$ & $8(57.1)$ & \\
\hline Very satisfied & & $8(47.1)$ & $5(35.7)$ & \\
\hline \multicolumn{5}{|l|}{ Satisfaction with faculty availability for mentorship } \\
\hline Not at/slightly all satisfied & & & $10(37.0)$ & \\
\hline Somewhat satisfied & & & $11(42.3)$ & \\
\hline Very/extremely satisfied & & & $5(18.5)$ & \\
\hline \multicolumn{5}{|c|}{ Impact of Antiracism Movement and Pandemic on Scholarship } \\
\hline $\begin{array}{l}\text { Impact of antiracism movement on interest in scholarship } \\
\text { in residency/career }\end{array}$ & & & & \\
\hline More interested & & & $14(51.9)$ & \\
\hline Less interested & & & $2(7.4)$ & \\
\hline Unsure/no & & & $11(40.7)$ & \\
\hline
\end{tabular}


Table 3: Continued

\begin{tabular}{|c|c|c|c|c|}
\hline & $\begin{array}{l}\text { Baseline } \\
\mathrm{n}=28(\%)\end{array}$ & $\begin{array}{c}\text { Year } 1 \\
\mathrm{n}=\mathbf{2 8}(\%)\end{array}$ & $\begin{array}{c}\text { Year } 2 \\
\mathrm{n}=\mathbf{2 7}(\%)\end{array}$ & $P$ Value \\
\hline \multicolumn{5}{|c|}{ Impact of Antiracism Movement and Pandemic on Scholarship } \\
\hline Desire more training on history of racism in research & & & $19(70.4)$ & \\
\hline $\begin{array}{l}\text { Changed topic or protocol due to antiracism movement } \\
\text { (PGY1-2 only) }\end{array}$ & & & $10(37.0)$ & \\
\hline \multicolumn{5}{|l|}{$\begin{array}{l}\text { Impact of pandemic on interest in scholarship in residency/ } \\
\text { career }\end{array}$} \\
\hline More interested & & & $11(40.7)$ & \\
\hline Less interested & & & $2(7.4)$ & \\
\hline Unsure/no & & & $14(51.9)$ & \\
\hline Changed topic or protocol due to pandemic (PGY1-2 only) & & & $11(40.7)$ & \\
\hline
\end{tabular}

Abbreviation: BU FM, Boston University Family Medicine.

${ }^{a}$ Question used in the Accreditation Council of Graduate Medical Education Annual Resident Survey

Table 4: Narrative Responses Regarding Curriculum and Mentorship,

Boston University Family Medicine Residents, 2018-2020

\begin{tabular}{|c|}
\hline Curriculum and Scholarship Environment \\
\hline $\begin{array}{l}\text { "I appreciate that there is now built in scholarship learning topics, [that are] informative and interactive, so that they feel } \\
\text { like useful learning opportunities." (PGY2) }\end{array}$ \\
\hline $\begin{array}{l}\text { "Currently, it doesn't feel like research is an expectation or a normal part of the culture of our FM residency program--it } \\
\text { feels like a shoehorned ACGME requirement that we MUST do in order to graduate." (PGY1) }\end{array}$ \\
\hline $\begin{array}{l}\text { "I think the faculty need to step up and be excited about projects and such to do with us. The residents can't carry this!" } \\
\text { (PGY3) }\end{array}$ \\
\hline $\begin{array}{l}\text { "Having a faculty and resident champion is key because of people like me who are feeling less interested in research } \\
\text { right now. If these things were not required or not getting critical feedback I would be less likely to put effort in to them." } \\
\text { (PGY2) }\end{array}$ \\
\hline $\begin{array}{l}\text { "Having a sense of what your minimum expectation is and then also robust support for those who are interested, so there } \\
\text { is an obvious low bar and also a high bar to motivate those who are interested to see the quality of work that could be } \\
\text { done." (PGY2) }\end{array}$ \\
\hline Mentorship \\
\hline $\begin{array}{l}\text { "[My mentor] is very knowledgeable and took the time to teach me basics of research and the many ways that I could } \\
\text { provide input." (PGY3) }\end{array}$ \\
\hline "My faculty mentor does not have research experience-makes it difficult to advance the project." (PGY3) \\
\hline
\end{tabular}

This evaluation has several limitations. It is an uncontrolled intervention in a single residency, implemented over only 2 years, resulting in a small sample size and $67 \%-77 \%$ response rate. However, our program shares many similarities with other urban, academic programs. Inclusion of ACGME survey questions enhances generalizability and narrative responses contextualize findings. We were unable to link individual responses from year to year, and we do not have complete data on scholarly activity prior to implementation, limiting our ability to identify change at the individual or program level. However, we are tracking scholarly output for future evaluation, as increases in conference submission and QI project participation may be early signs of more global output increases.

In conclusion, this study provides evidence that resident interest, confidence and participation in scholarly activity may be influenced by a scholarship curriculum that is longitudinal, driven by residents, and able to incorporate resident-identified topics in health research..$^{18}$ As resident scholarly pursuits increase, our findings highlight the need for faculty to enhance their own scholarly portfolios. To that end, endeavors at the national level to address faculty scholarship and research training pipelines are encouraging. ${ }^{22-25}$ The rising interest in scholarship as we confront health inequities laid bare by COVID-19 reinforces the need to train family physicians in the scholarly skills required to achieve health equity. 
PRIOR PRESENTATIONS: Standish K, Gonzalez S, McGuire C, Saper R. "Increased resident confidence in scholarly activities after year one of a redesigned scholarship curriculum." Accepted oral presentation presented as virtual prerecorded presentation, Society of Teachers of Family Medicine Annual Conference, August 24-27, 2020 .

CORRESPONDING AUTHOR: Address correspondence to Dr Katherine R. Standish, 1 Boston Medical Center Place, Dowling 5 South, Boston, MA 02118-2393. 617-414-4465. Fax: 617-414-3345.

\section{References}

1. Saultz J. Scholarship and residency programs. Fam Med. 2011;43(5):309-310.

2. Berwick DM, Finkelstein JA. Preparing medical students for the continual improvement of health and health care: abraham Flexner and the new "public interest". Acad Med. 2010;85(9)(suppl):S56-S65. doi:10.1097/ ACM.0b013e3181ead779

3. Hubinette M, Dobson S, Scott I, Sherbino J. Health advocacy. Med Teach. 2017;39(2):128135. doi:10.1080/0142159X.2017.1245853

4. Wood W, McCollum J, Kukreja P, et al. Graduate medical education scholarly activities initiatives: a systematic review and meta-analysis. BMC Med Educ. 2018;18(1):318. doi:10.1186/s12909-018-1407-8

5. Accreditation Council for Graduate Medical Education. ACGME Program Requirements for Graduate Medical Education in Family Medicine. 2020. https://www.acgme.org/Portals/0/ PFAssets/ProgramRequirements/120_FamilyMedicine_2020.pdf. Accessed March 13, 2021.

6. Crawford P, Seehusen D. Scholarly activity in family medicine residency programs: a national survey. Fam Med. 2011;43(5):311-317.

7. Brown SR, Miser WF. Meeting scholarly activity requirements in a family medicine residency program. Ann Fam Med. 2017;15(5):487-488. doi:10.1370/afm.2130
8. Stevenson MD, Smigielski EM, Naifeh MM Abramson EL, Todd C, Li STT. Increasing scholarly activity productivity during residency: A systematic review. Acad Med. 2017;92(2):250 266. doi:10.1097/ACM.0000000000001169

9. Noble C, Billett SR, Phang DTY, Sharma S, Hashem F, Rogers GD. Supporting resident research learning in the workplace: A rapid realist review. Acad Med. 2018;93(11):1732 1740. doi:10.1097/ACM.0000000000002416

10. Seehusen DA, Ledford CJW, Grogan S, et al. A point system as catalyst to increase resident scholarship: an MPCRN study. Fam Med. 2017;49(3):222-224

11. Seales SM, Lennon RP, Sanchack K, Smith DK. Sustainable Curriculum to Increase Scholarly Activity in a Family Medicine Residency. Fam Med. 2019;51(3):271-275. doi:10.22454/ FamMed.2019.906164

12. Carek PJ, Dickerson LM, Diaz VA, Steyer TE. Addressing the Scholarly Activity Requirements for Residents: One Program's Solution. J Grad Med Educ. 2011;3(3):379-382 doi:10.4300/JGME-D-10-00201.1

13. Hoedebecke K, Rerucha C, Runser L. Increase in residency scholarly activity as a result of resident-led initiative. Fam Med. 2014;46(4):288-290.

14. Lennon RP, Oberhofer AL, McNair V, Keck JW Curriculum changes to increase research in a family medicine residency program. Fam Med. 2014;46(4):294-298

15. American Academy of Family Physicians. Scholarly Activity and Information Mastery. 2015 https://www.aafp.org/dam/AAFP/documents/medical_education_residency/program directors/Reprint280_Scholarly.pdf. Accessed March 13, 2021

16. Kanna B, Deng C, Erickson SN, Valerio JA, Dimitrov V, Soni A. The research rotation: competency-based structured and novel approach to research training of internal medicine residents. BMC Med Educ. 2006;6(Im):1-8.
17. Fancher TL, Wun T, Hotz CS, Henderson MC. Jumpstarting academic careers with a novel intern research rotation: the AIMS rotation. Am J Med. 2009;122(11):1061-1066. doi:10.1016/j.amjmed.2009.06.017

18. Lennon RP, Fuentes RWC, Broszko C, Koch JJ, Sanchack K, Keck JW. A Curriculum to increase resident scholarly activity. Fam Med. 2020;52(8):557-561. doi:10.22454/ FamMed.2020.257274

19. Himelhoch S, Edwards S, Ehrenreich M, Luber MP. Teaching lifelong research skills in residency: implementation and outcome of a systematic review and meta-analysis course. J Grad Med Educ. 2015;7(3):445-450. doi:10.4300/JGME-D-14-00505.1

20. Cafferty LA, Crawford PF, Jackson JT, Ledford CJW. Residency leader motivations to engage residents and residency faculty in scholarship: a qualitative study. Fam Med. 2020;52(8):581585. doi:10.22454/FamMed.2020.437433

21. Das SU, Bar-On ME. Innovative strategies to increase resident scholarly activity and engage faculty support. J Investig Med. 2018;66(1):e2e3. doi:10.1136/jim-2017-000550

22. Ewigman B, Davis A, Vansaghi T, et al. Building research \& scholarship capacity in departments of family medicine: a new joint ADFM-NAPCRG initiative. Ann Fam Med. 2016;14(1):82-83. doi:10.1370/afm.1901

23. Liaw W, Petterson S, Jiang V, et al. The scholarly output of faculty in family medicine departments. Fam Med. 2019;51(2):103-111. doi:10.22454/FamMed.2019.536135

24. Lawson PJ, Smith S, Mason MJ, et al. Creating a culture of inquiry in family medicine. Fam Med. 2014;46(7):515-521.

25. Doubeni CA, Davis A, Benson JL, Ewigman B. A Physician scientist pathway in family medicine residency training programs. Ann Fam Med. 2017;15(6):589-590. doi:10.1370/ afm. 2160 